\title{
A Facile Microwave-Assisted Hydrothermal Synthesis of Graphene Quantum Dots for Organic Solar Cell Efficiency Improvement
}

\author{
Thi Thu Hoang $\mathbb{D}^{1}{ }^{1}$ Hoai Phuong Pham $\mathbb{D}^{1,2}$ and Quang Trung Tran $\mathbb{D}^{1}$ \\ ${ }^{1}$ Faculty of Physics, University of Science, Vietnam National University Ho Chi Minh City (VNU-HCM), 227 Nguyen Van Cu Street, \\ District 5, Ho Chi Minh City 72711, Vietnam \\ ${ }^{2}$ Faculty of Science, Dong Nai University, 4 Le Quy Don Street, Tan Hiep Ward, Bien Hoa City 76111, Vietnam
}

Correspondence should be addressed to Thi Thu Hoang; htthu@hcmus.edu.vn

Received 12 November 2019; Revised 14 January 2020; Accepted 30 January 2020; Published 11 February 2020

Guest Editor: Anagh Bhaumik

Copyright ( 92020 Thi Thu Hoang et al. This is an open access article distributed under the Creative Commons Attribution License, which permits unrestricted use, distribution, and reproduction in any medium, provided the original work is properly cited.

Carbon-based nanomaterials have successively remained at the forefront of different research fields and applications for years. Understanding of low-dimension carbon material family (CNT, fullerenes, graphene, and graphene quantum dots) has arrived at a certain extension. In this report, graphene quantum dots were synthesized from graphene oxide with a microwave-assisted hydrothermal method. Compared with conventional time-consuming hydrothermal routes, this novel method requires a much shorter time, around ten minutes. Successful formation of quantum dots derived from graphene sheets was verified with microscopic and spectroscopic characterization. Nanoparticles present a diameter of about 2-8 nm, blue emission under ultraviolet excitation, and good dispersion in polar solvents and can be collected in powder form. The synthesized graphene quantum dots were utilized as a hole transport layer in organic solar cells to enhance the cell quantum efficiency. Such quantum dots possess energy levels (Ec and $\mathrm{Ev}$ ) relevant to HOMO and LUMO levels of conductive polymers. Mixing P3HT:PCBM polymer and graphene quantum dots of sufficient extent notably helps reduce potential difference at interfaces of the two materials. Overall efficiency consequently advances to $1.43 \%$, an increase of more than $44 \%$ compared with pristine cells $(0.99 \%)$.

\section{Introduction}

Organic solar cells (OSC), a highly promising branch in the grand photovoltaic tree, draw considerable involvement from either research or development sectors. They hold various important advantages like environment-friendliness, low cost, large-area production and simple fabrication techniques (screen-printing, spin-coating, and spray pyrolysis) [1-4]. They are excellent candidates for power-supplying applications which require light weight, great mechanical flexibility, and high foldability. The most prevalent heterojunction structure based on P3HT:PCBM host material has been regularly reported with promising achievements [5-7]. However, for forthcoming development, the overall efficiency must be further enhanced.

Up to this time, different scenarios have been proposed to boost cell efficiency [8-10]. Among them, one commonly accepted method is to integrate organic solar cells with inor- ganic nanostructured materials ( $\mathrm{CdSe}, \mathrm{CdS}$, and $\mathrm{PbSe}$ ) to constitute hole/electron transport, hole/electron extract, or hole/electron blocking layers [11]. Such layers play a significant role in creating intermediate energy levels, well-fitting for Ec, Ev levels of active layers in optoelectronic devices, to reduce potential barrier difference between active layers and electrodes or between active layers themselves. This arrangement will help to raise the possibility of carrier collection at the electrodes and, therefore, increase the cell efficiency [ 1 , $2,4,9,12,13]$. However, by virtue of high toxicity in their nature, CdSe and CdS have gradually been substituted by environment-green materials $[6,14]$. Graphene quantum dot (GQD) is a superior alternative thanks to its quantum confinement and edge effects. In addition, it also shows other great properties like nontoxicity, good dispersion in polar solvents, optical stability, and bandgap tunability $[1,2,15-$ 17]. Kim et al. [18] reported successful synthesis of GQDs and reduced GQDs and investigated their influence on 
efficiency of OSC. When GQDs were mixed especially with PEDOT:PSS to construct a hole transport layer, cell efficiency increased from $7.52 \%$ to $8.17 \%$. Meanwhile, if both GQDs and rGDQs were mixed with PEDOT:PSS, the efficiency increased up to $8.67 \%$. Ding et al. [19] reported the increment of cell efficiency from $5.27 \%$ to $7.91 \%$ by utilizing GQDs as a hole extraction layer. In addition to working as a hole transport or hole extraction layer, GQDs also work very sufficiently as a buffer layer of electrode [3]. Wang et al. [1] employed GQDs in cathode interfacial layers in ITO/ZnO/GQDs/PTB7:PC71BM/ $/ \mathrm{MoO}_{3} / \mathrm{Al}$ structure and boosted the efficiency to $10.14 \%$ compared to $8.76 \%$ of the same architecture without GQDs. Tsai et al. [15] adopted GQDs as down converter material in n-type Si heterojunction solar cells and increased the efficiency from $14.77 \%$ to $16.55 \%$. Currently, this can be recognized as an ideal value; however, solar cells with GQDs are still of high potential and their efficiencies are predicted to overcome the theoretical number of $30 \%$ [20].

GQDs were produced with electron beam irradiation [21] or ruthenium-catalyzed C60 [22] conversion methods. They required specialized instruments and high-cost material but production efficiency was quite low [23]. Currently, GQDs have been synthesized through hydrothermal or direct electrochemical approaches from different raw materials like carbon fiber, carbon black, graphite flakes, graphite rods, or multiwall carbon nanotubes. These processes were more economical but time-consuming (several days) [24]. They also relied heavily on a good filtering system and remarkably high-speed centrifuge to rinse and separate GQDs from acidic solvents.

Therefore, a rapid, simple, efficient, cost-effective, and energy-saving method for graphene quantum dots of high quality is urgently in need. Interestingly, microwavesupported processes can fulfill all those requirements at the highest level. At present, they receive huge attention from materials scientists, chemists, and physicists thanks to the fact that carbon-based materials present strong interaction with microwave and promptly generate huge localized heat [25]. Nguyen et al. [25] utilized microwave in combination with hydrothermal route for GQDs and nitrogen-doped GQD synthesis. They also investigated the heating duration and microwave power for best luminescent products. Yang et al. [26] succeeded in fabricating nitrogen-doped carbon quantum dots for biosensing applications. High-quality graphene quantum dots synthesized with microwave assistance have been widely used in biomedical [27], photocatalytic [28], sensing [29], energy [30], and fuel cell [31] applications.

In this paper, we report the successful synthesis of GQDs from graphene oxide via a one-step top-down method by using reducing agent $\mathrm{NH}_{3}$ and thermal energy from microwave oven to oxidize raw graphene oxide. The proposed method is low cost and less time-consuming (about ten minutes) compared with the conventional hydrothermal method (about hours). As a proof of concept, we also used GQDs as a hole transport layer in our ITO/PEDOT:PSS/P3HT:PCBM:GQDs/Al cell design and investigated its effectiveness on the quantum efficiency of organic solar cells.

\section{Experiments}

2.1. Materials. Graphite flake (GF), P3HT, PCBM were purchased from Sigma-Aldrich; PEDOT from Clevios; and $\mathrm{HNO}_{3}, \mathrm{NaNO}_{3}, \mathrm{H}_{2} \mathrm{SO}_{4}, \mathrm{KMnO}_{4}, \mathrm{H}_{2} \mathrm{O}_{2}$, ammonia solution (25 wt. \%), and dichlorobenzene (DCB) from Xilong.

2.2. Fabrication of Graphene Oxide. At first, 0.4 gram of graphite flake (GF) and $0.2 \mathrm{~g}$ of $\mathrm{KMnO}_{4}, 0.4 \mathrm{ml}$ of pure $\mathrm{HNO}_{3}$, in weight ratio of $2: 1: 2$, were mixed in two minutes and then heated in a microwave oven at 700 Watts in one minute to produce exfoliated graphite.

Consequently, 0.4 gram of exfoliated graphite, 0.2 gram of $\mathrm{NaNO}_{3}$, and $9.6 \mathrm{ml}$ of pure $\mathrm{H}_{2} \mathrm{SO}_{4}$ were mixed in a beaker, then, 4.0 gram of $\mathrm{KMnO}_{4}$ was gradually added. This mixture was under continuous moderate stirring at room temperature in 24 hours. A quantity of $8 \mathrm{ml}$ pure water was supplied to promote the reaction so that graphite could totally exfoliate into single-layered entities. Then, the mixture was diluted with $20 \mathrm{ml}$ of pure water two times. Finally, $10 \mathrm{ml}$ of $\mathrm{H}_{2} \mathrm{O}_{2}$ was provided to turn $\mathrm{MnO}_{4^{-}}$and $\mathrm{MnO}_{2}$ into $\mathrm{Mn}+$ ions in the solution. Graphene oxide solution of bright yellow color was collected. Nonreacted black graphite flakes were filtered out. For long-time preservation, the obtained solution was centrifuged at 7000 round per minute with distilled water to make it neutral.

2.3. Fabrication of Graphene Quantum Dots. A volume of $5 \mathrm{ml}$ of graphene oxide as obtained above, $10 \mathrm{ml}$ of distilled water and $2 \mathrm{ml}$ of ammonia solution were mixed with magnetic stirrer and sent into a Teflon container. The container was kept in a protective box and heated in a microwave oven at 700 Watts in 10 minutes.

The product was cooled down gradually to room temperature; then, dialysis bag $2000 \mathrm{Da}$ (Spectrum lab) was used to remove contaminants and big-size grains. The acquired solution was baked at $80^{\circ} \mathrm{C}$ in 1 hour to eliminate residual $\mathrm{NH}_{3}$. The final GQDs in powder form were collected with a rotavapor.

2.4. Fabrication of Organic Solar Cells. To investigate the performance of GQDs as an effective hole transport material, two structures of organic solar cells ITO/PEDOT:PSS/P3HT: $\mathrm{PCBM} / \mathrm{Al}$ and ITO/PEDOT:PSS/P3HT:PCBM:GQDs/Al were fabricated as illustrated in Figure 1.

Cell construction followed the procedure: ITO substrates of $4 \mathrm{~mm} \times 10 \mathrm{~mm}$ and sheet resistance of $10 \Omega / \square$ were rinsed and exposed to UV light $(365 \mathrm{~nm})$ in 20 minutes. The PEDOT:PSS layer was spin-coated onto ITO substrate. The samples went through heat treatment of $140^{\circ} \mathrm{C}$ in 10 minutes in argon ambient air to stabilize the PEDOT:PSS on ITO substrates. After that, $18 \mathrm{mg}$ of P3HT and $18 \mathrm{mg}$ PCBM were mixed in $2 \mathrm{ml}$ of dichlorobenzene (DCB), shaken well at $70^{\circ} \mathrm{C}$ in 60 minutes. The P3HT:PCBM mixture was spincoated onto PEDOT:PSS and remained some time in inert environment until the DCB solvent dried out. Samples were heated at $110^{\circ} \mathrm{C}$ in 10 minutes. Finally, aluminum electrodes of $4 \mathrm{~mm} \times 2 \mathrm{~mm}$ were thermally evaporated. The final cells were baked at $100^{\circ} \mathrm{C}$ in 10 minutes in argon air. 


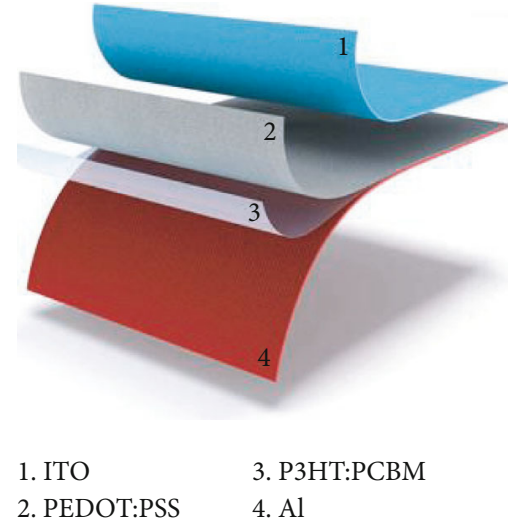

(a)

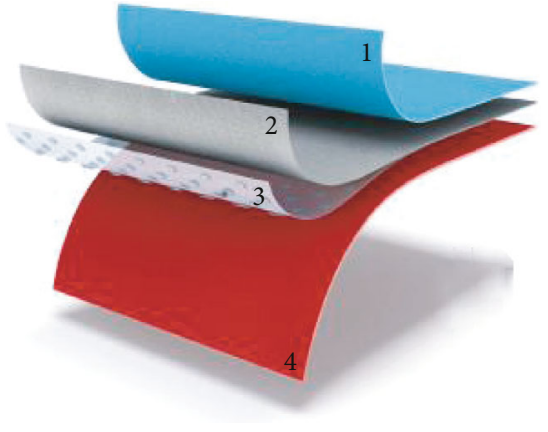

1. ITO

2. PEDOT:PSS

4. Al

(b)

FIGURE 1: Organic solar cell structures with (b) and without (a) a hole transport layer.

For cells which used GQDs as hole transport layers, GQD powder was mixed with P3HT:PCBM solution in 1, 2, 3, and $4 \mathrm{mg}$ series and shaken well at $70^{\circ} \mathrm{C}$ in 30 minutes. Lasting steps followed procedure as described above. This mixing gives a sample sequence, namely, GQD-1, GQD-2, GQD-3, and GQD-4.

Morphology and crystal structure of GQDs were characterized with transmission electron microscopy (TEM-JEOL JEM 1400) and X-ray diffraction spectroscopy (XRD-D8 ADVANCE, $\mathrm{Cu} \mathrm{K} \alpha$ radiation $\lambda=1.54 \AA$ ). The electronic states and carbon bonding of GQDs were investigated with $\mathrm{X}$-ray photoemission spectroscopy (XPS-K-Alpha/Thermo scientific, X-ray source: monochromatic $\mathrm{Al} \mathrm{K} \alpha$ ) and Fourier transform infrared spectroscopy (FTIR-Equinox 550). Absorption spectra of GQDs in water were measured with Jasco V530. The photoluminescence spectra were taken with a HORIBA fluorescence spectrophotometer using laser He$\mathrm{Cd} 325 \mathrm{~nm}$ as an exciting source. The J-V characteristic curves of cells were measured with Keithley 2400.

\section{Results and Discussion}

The scanning electron microscopic image of graphene oxide sheets was illustrated in Figure 2. The graphene oxide sheets were quite thin and $5 \mu \mathrm{m}$ wide, approximately. The transmission electron microscopic image in Figure 3 also shows graphene quantum dots of spherical shape, no agglomeration, and a size from 2 to $8 \mathrm{~nm}$. The average particle size was approximately $4.1 \mathrm{~nm}$, and margin of error was 0.3 (for $90 \%$ confidential level). Generally, size distribution of nanoparticles derived from top-down approaches is believed to be nonuniform, and abundant raw materials such as CNT, coal, graphite, or graphene oxide still remain after all. However, these methods are rather simple and easy to implement and provide quantum dots of high crystallinity $[16,17,23$, 32]. Luo et al. [30] reported the synthesis of graphene quantum dots from graphite, and their high-resolution transmission electron microscopic images showed excellent crystallinity and lattice spacing of about $0.335 \mathrm{~nm}$. Peng et al. [23] presented the TEM and AFM images, in which graphene quantum dot size varied from 1 to $4 \mathrm{~nm}$ and consisted of 1 to

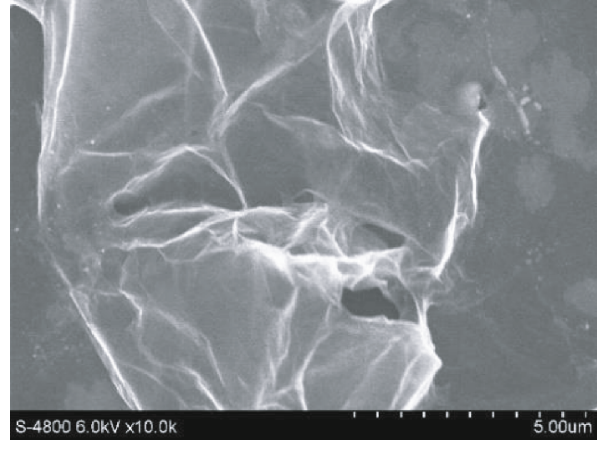

FIGURE 2: SEM image of graphene oxide sheets.

3 graphene layers. Graphene quantum dots of high quality synthesized from graphene oxide sheets were also demonstrated in the work of Tetsuka et al. [33]. Those quantum dots had good dispersion in water, a size of $2.5 \mathrm{~nm}$, and a thickness of $1.13 \mathrm{~nm}$.

The existence of functional groups in GQD and GO solutions after a microwave-assisted hydrothermal process was characterized with Fourier transform infrared spectroscopy (FTIR) and is illustrated in Figure 4. As reported so far, most GQDs consisted of surface functional groups like hydroxyl $(-\mathrm{OH})$, epoxy (-O-), carbonyl $(-\mathrm{C}=\mathrm{O})$, and carboxyl acid $(-\mathrm{COOH})[23,32,34]$. The FTIR spectrum of $\mathrm{NH}_{3}$-reduced samples presents several peaks at $550 \mathrm{~cm}^{-1}, 1250 \mathrm{~cm}^{-1}$, $3300-3600 \mathrm{~cm}^{-1}$, and $1650 \mathrm{~cm}^{-1}$, corresponding to in-plane vibration of $\mathrm{C}-\mathrm{O}-\mathrm{C}$ and $\mathrm{C}-\mathrm{N}$ bonding, in-plane stretching of N-H in amine groups. Peak at especially $1650 \mathrm{~cm}^{-1}$ corresponds to typical vibration of the amide-carbonyl group. This confirmed the formation of amide groups through the interaction between carboxylic groups in lattice $[1,33]$.

Photoelectron spectroscopic (XPS) results in Figures 5(a) and 5(b) already point out the two well-known peaks $\mathrm{C} 1 \mathrm{~s}$ and N1s of GQDs. The C1s peak confirms the existence of $\mathrm{C}=\mathrm{C}$ bonding $(284.6 \mathrm{eV})$ equivalent to $\mathrm{sp}_{2}$ carbon aromatic rings, epoxy C-O-C bonding $(286.4 \mathrm{eV})$, and carboxyl $\mathrm{O}-\mathrm{C}=\mathrm{O}$ bonding $(288.8 \mathrm{eV})$ [35]. These conventional bonding are rather common in GQDs derived from the hydrothermal 

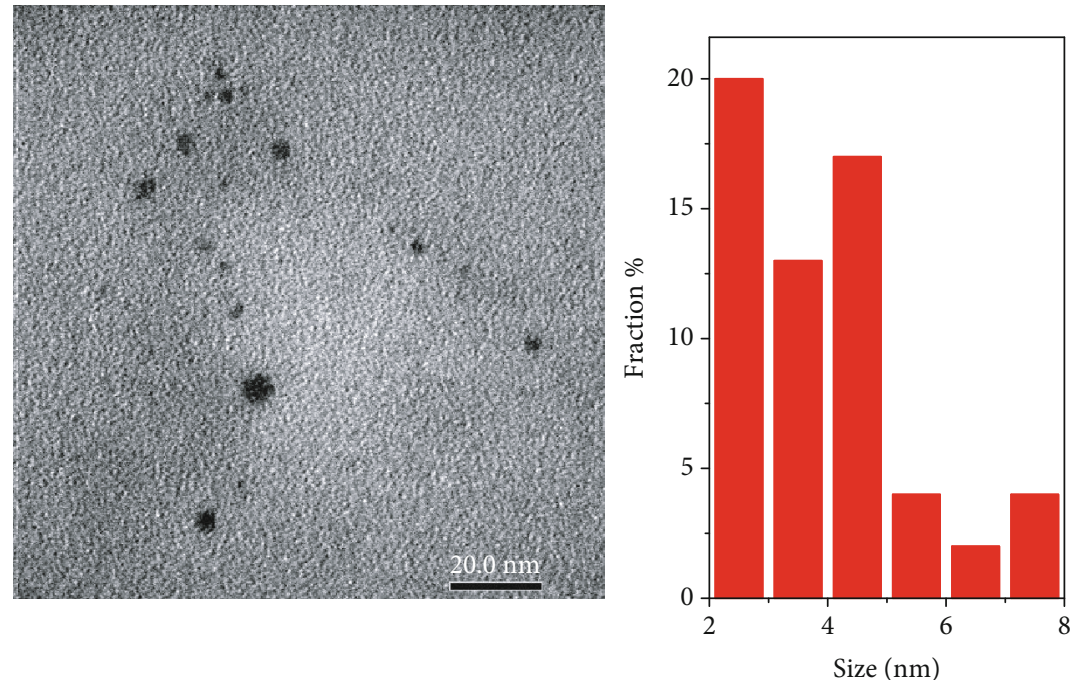

FIGURE 3: TEM image of graphene quantum dots and their size distribution (from 2 to $8 \mathrm{~nm}$ ).

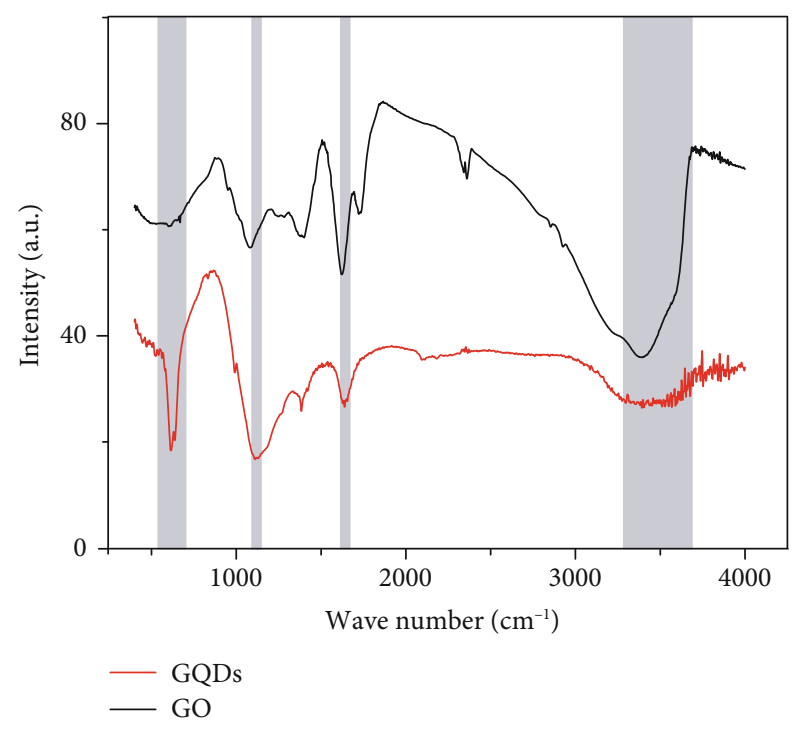

Figure 4: Fourier transform infrared transmission spectra of graphene oxide (black) and graphene oxide quantum dots (red).

method. Those functional groups bring GQDs' great dissolution in polar solvents $[1,23,34,36]$. Peak N1s at $401 \mathrm{eV}$ represents the connection between graphene and $\mathrm{C}-\mathrm{NH}_{2}$ amine groups. This proves that $\mathrm{NH}_{3}$ adsorbed onto functional groups of GO sheets and thermal effect of microwave helped to cut these bondings and create GQDs of smaller size [33].

The crystal structures of the graphite flakes, graphene oxide, and GQDs were characterized by XRD, and the results are displayed in Figure 6. The XRD pattern of the graphite flakes (Figure 6(a)) showed a well defined $\left(\begin{array}{lll}0 & 0 & 2\end{array}\right)$ peak at $26.5^{\circ}$ (d-spacing: $0.335 \mathrm{~nm}$ ). The appearance of a new peak at $10.6^{0}$ (d-spacing: $0.8 \mathrm{~nm}$ ) and the complete vanish of the original $\left(\begin{array}{lll}0 & 0\end{array}\right)$ peak of graphite flakes indicate the successful formation of graphene oxide. The interlayer spacing of graphene oxide is still a little larger than the $\mathrm{d}$-spacing of graph- ite. This result could be attributed to the oxygen-containing groups introduced during the exfoliation and oxidation of graphite flakes, which enlarged the interlayer spacings.

After the chemical reduction with $\mathrm{NH}_{3}$ and microwaveassisted hydrothermal process, the oxygen-containing functional groups have been reduced. Therefore, the interlayer spacing also decreased, which was shown through the shift of GQD diffraction peak from $10.6^{\circ}$ to $21.7^{\circ}$. The new interlayer spacing is $0.403 \mathrm{~nm}$, which is broader than that of graphite.

The X-ray diffraction spectrum of GQDs synthesized from carbonized citric acid $[37,38]$ showed that the corresponding value of interlayer spacing is about $0.34 \mathrm{~nm}$, similar to that of bulk graphite $(0.34 \mathrm{~nm})$; meanwhile, spacing between layers of GQDs synthesized from carbon fibers [23] is much higher (about $0.403 \mathrm{~nm}$ ). This is assumed to be due to the oxygen-containing functional groups existing between layers during the reduction and exfoliation process of carbon fibers with strong dense acids. Layer spacing of GQDs derived from the hydrothermal process with an $\mathrm{NH}_{3}$ reducer is about $0.393 \mathrm{~nm}$. In general, oxygen-containing functional groups may widen the space between GQD layers. Such opening may depend on the position of those groups whether they lie between layers or at the edges.

The absorption spectra of GO and GQDs are depicted in Figure 7(a). GQD solution show high absorbance in the UV region with a tail extending out into visible range. In absorption spectrum of GO, two peaks can been observed: one higher peak at $230 \mathrm{~nm}$ due to $\pi-\pi^{*}$ transition of $\mathrm{C}=\mathrm{C}$ bonding and aromatic rings [39], the lower one at $300 \mathrm{~nm}$ originates from $\mathrm{n}-\pi^{*}$ of $\mathrm{C}=\mathrm{O}$ bonding. In the case of GQDs, the peak of $\pi-\pi^{*}$ transition lies in the $220-270 \mathrm{~nm}$ range and the peak of $\mathrm{n}-\pi^{*}$ transition is located at a longer wavelength of $260 \mathrm{~nm}[13,37,40]$.

Figure 7(b) shows the photoluminescence of GQDs under UV excitation of $365 \mathrm{~nm}$. The spectrum contains a single peak of $443 \mathrm{~nm}$, like the report of Pan et al. [41]. The widening of PL spectrum shows the nonuniform size distribution 


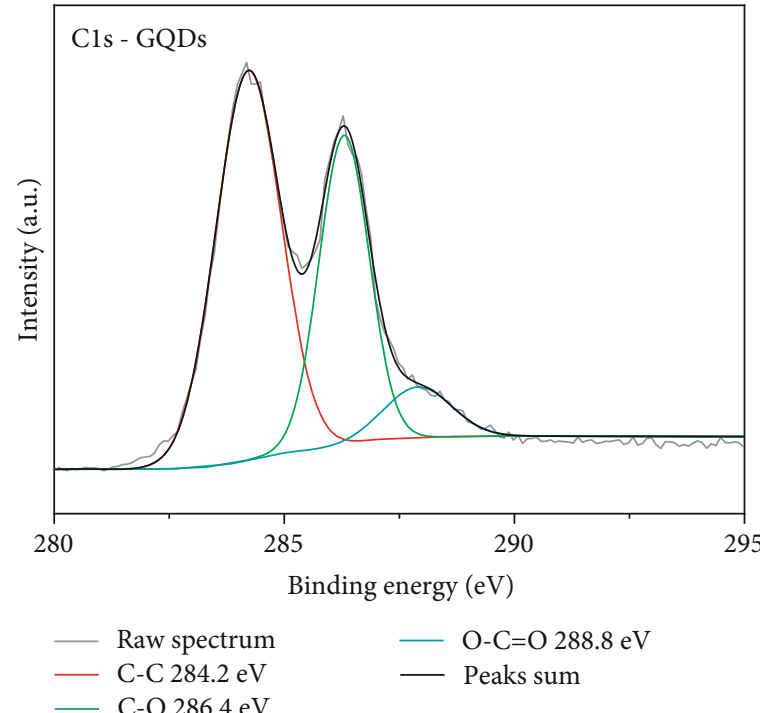

(a)

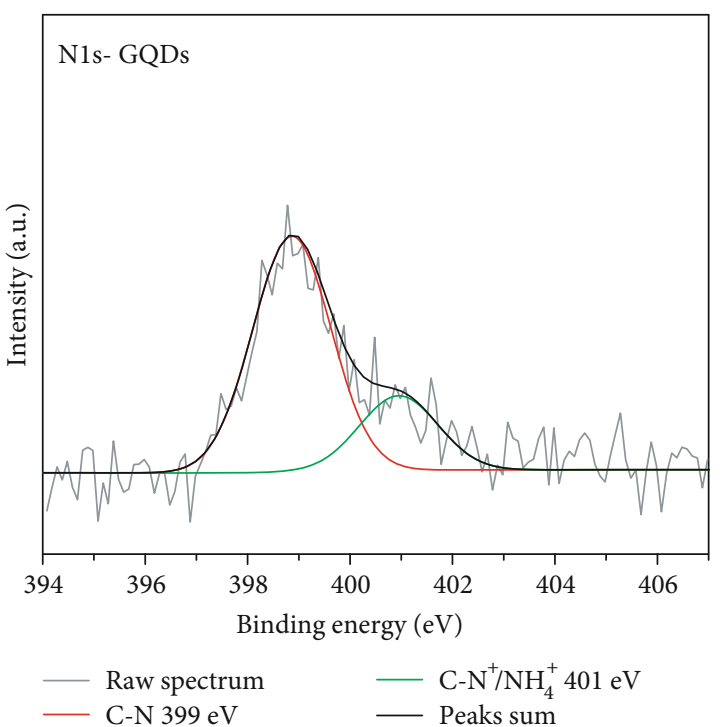

(b)

FIGURE 5: The XPS spectra of graphene quantum dots.

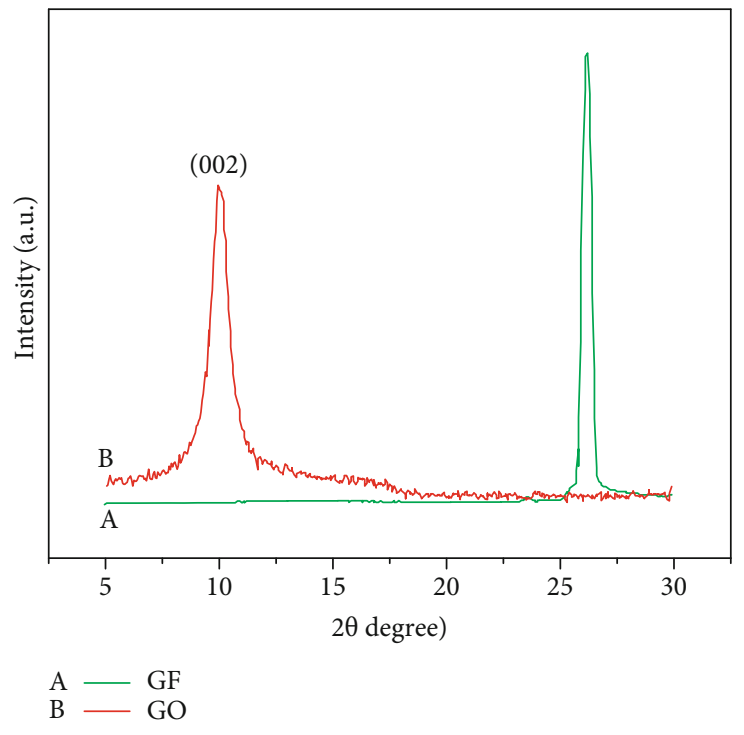

(a)

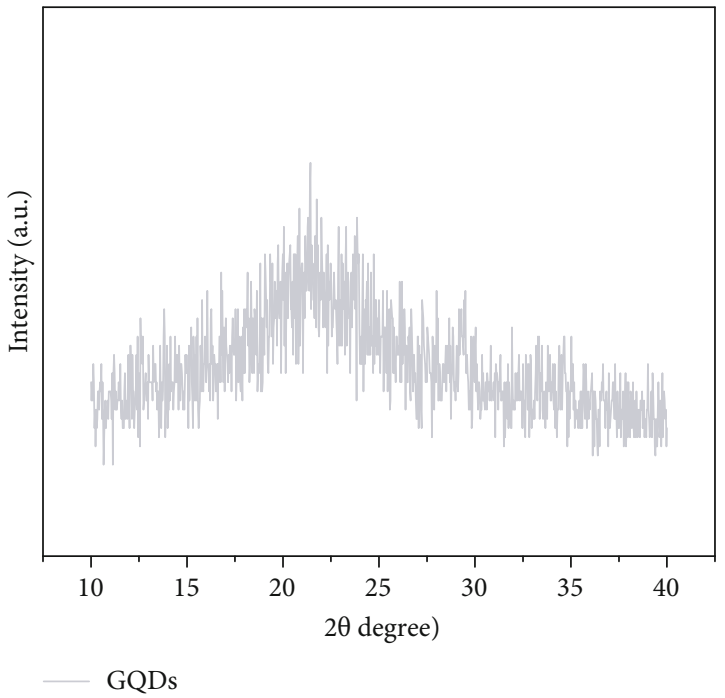

(b)

FIGURE 6: The X-ray diffraction spectrum of GF, GO (a), and GQDs (b)

of GQDs around $5 \mathrm{~nm}$, which corresponds to the TEM result in Figure 3. In principle, a smaller GQD size will shift the peak toward a shorter wavelength (blueshift) $[1,16,34,42]$ and the GQD bandgap can be modulated through controlling chemical functional groups or particle size $[23,34]$. This is of crucial importance in optical applications $[1,4,15,20]$.

In organic solar cells, interlayers locating between active layers and electrodes play an important role in achieving high overall efficiency as well as device stability $[4,6,9,12,19]$. Functioning as intermediate buffering layers, they help to reduce the potential difference between active layers and electrodes so that electrons and holes can be effectively separated to both sides and carrier collection at the electrodes can be intensified. The required interlayers must have good transparency, high electric conduction, and good chemical stability. Their Ec and Ev levels must somehow correspond to HOMO and LUMO of conductive polymers. GQDs can greatly satisfy those requirements and also help to boost enhance the absorption ability of P3HT:PCBM mixture [6]. At present, GQDs are recognized as an effective hole transport material in organic solar cells.

To study the effect of GQD dopant in an active layer, solar cell samples of different GQD doping amounts from 0 milligram (reference sample, no doping) to $1,2,3$, and 4 


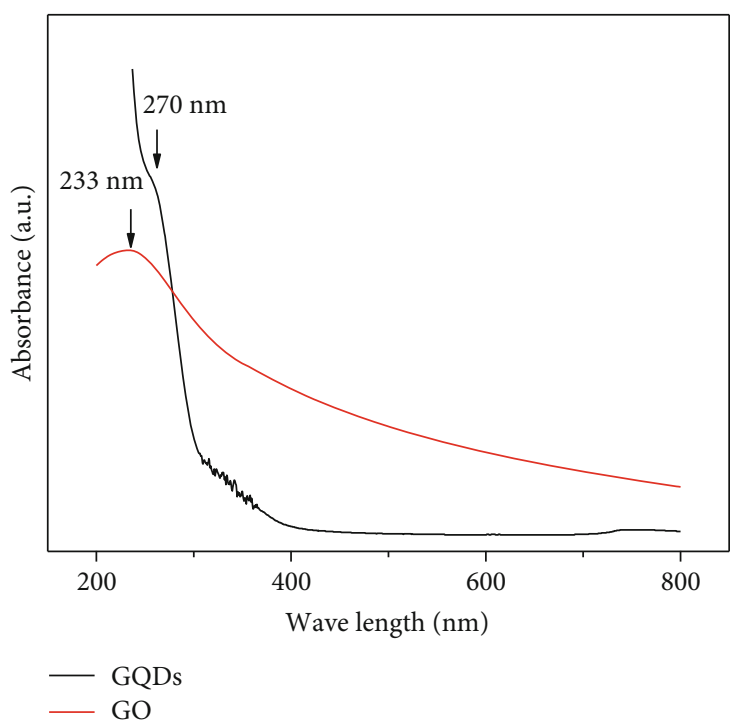

(a)

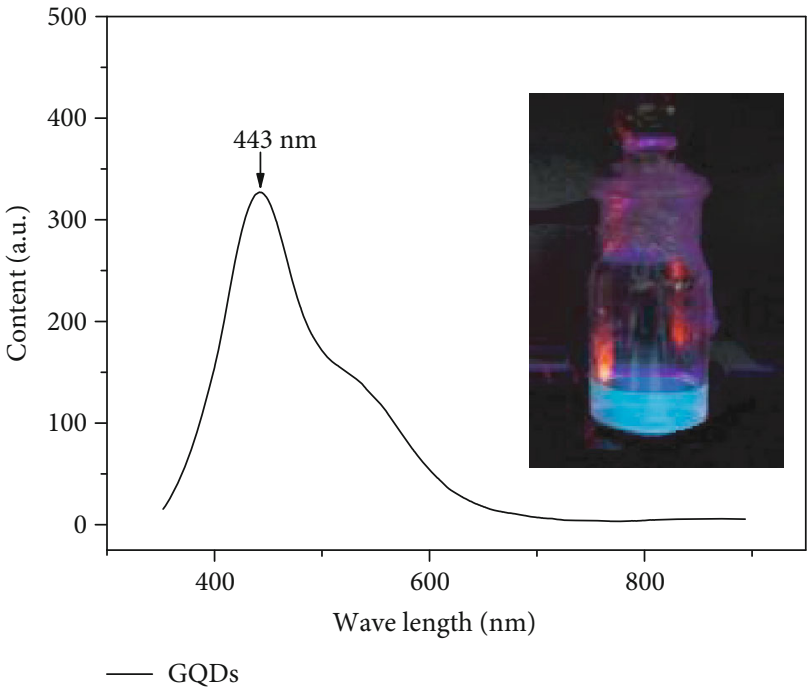

(b)

FIGURE 7: UV-visible absorption spectra of GQDs and GO (a) and photoluminescence spectrum of GQDs (b). Strong emission of GQDs under UV lamp (365 nm) excitation (inset).

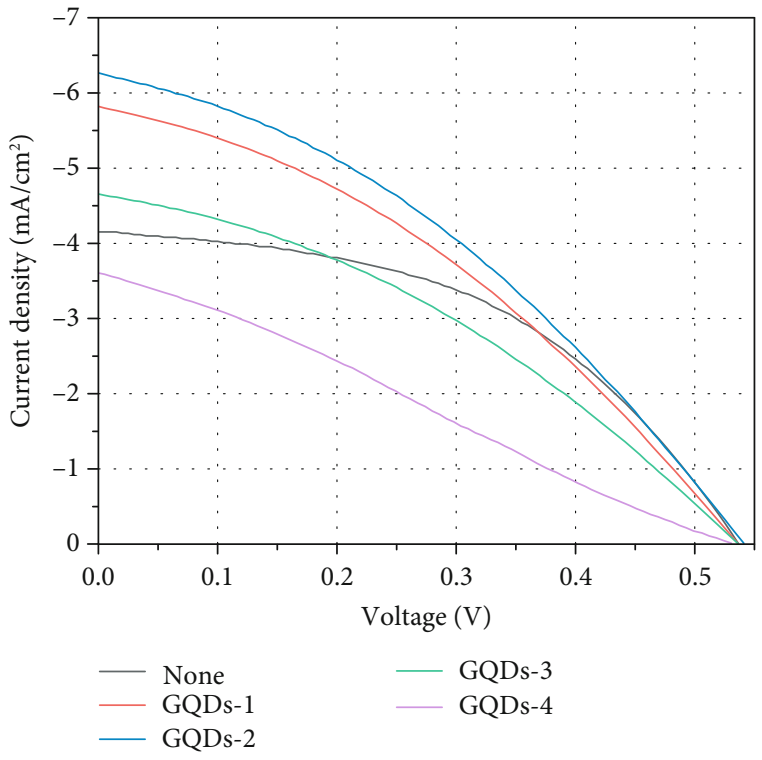

(a)

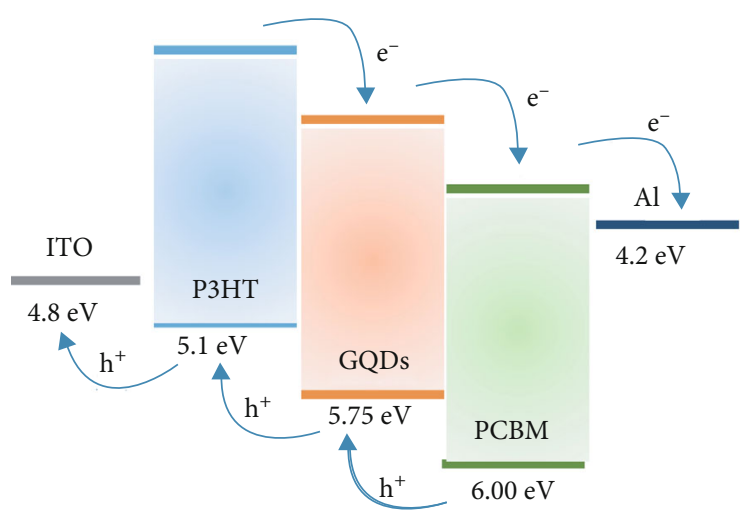

Figure 8: $J-V$ characteristics of organic solar cells at different graphene quantum dot doping amounts (a) and energy band diagram of graphene quantum dot-doped organic solar cells (b). The highest occupied molecular orbital and lowest unoccupied molecular orbital values of the P3HT, PCBM, and GQDs from the literature [6].

milligrams. Solar cell structure ITO/PEDOT: PSS/P3HT: PCBM:GQDs/Al was designed and fabricated.

Figure 8 illustrates the $J-V$ characteristics of constructed organic solar cells. Important values of short-circuit currents $\left(J_{\mathrm{sc}}\right)$, open-circuit voltages $\left(V_{\mathrm{oc}}\right)$, fill factors $(\mathrm{FF})$, and power conversion efficiency (PCE) of solar cell samples are listed in Table 1 .

The $J-V$ characteristics in Figure 8(a) show that the GQD-doped solar cell samples have higher short-circuit values than the nondoped ones, while the open-circuit
TABLE 1: Photovoltaic values of organic solar cells on different GQD doping level.

\begin{tabular}{lcccc}
\hline P3HT:PCBM/GQDs & $J_{\text {SC }}\left(\mathrm{mA} / \mathrm{cm}^{2}\right)$ & $V_{\mathrm{OC}}(\mathrm{V})$ & FF $(\%)$ & PCE (\%) \\
\hline None & 4.11 & 0.54 & 45 & 0.99 \\
GQD-1 & 5.81 & 0.54 & 41 & 1.28 \\
GQD-2 & 6.31 & 0.54 & 42 & 1.43 \\
GQD-3 & 4.65 & 0.54 & 38 & 0.95 \\
GQD-4 & 3.59 & 0.54 & 23 & 0.45 \\
\hline
\end{tabular}


voltages remain the same. With undoped samples, the short-circuit current density $\left(J_{\mathrm{SC}}\right)$ is about $4.11 \mathrm{~mA} / \mathrm{cm}^{2}$, open-circuit voltage $\left(V_{\mathrm{OC}}\right)$ is about $0.54 \mathrm{~V}$, fill factor 0.49 , and efficiency $0.99 \%$. With samples of 2 milligram QGD dopant, $J_{\mathrm{SC}}$ increases up to $6.31 \mathrm{~mA} / \mathrm{cm}^{2}, V_{\mathrm{OC}}$ is still $0.54 \mathrm{~V}$, fill factor reaches 0.42 , and the overall efficiency rises to $1.43 \%$. Such increment of overall efficiency may be due to the ladderlike energy levels situating in order of $E_{\mathrm{cP} 3 \mathrm{HT}}<E_{\mathrm{cGQDs}}<$ $E_{\mathrm{cPCBM}}$ and $E_{\mathrm{vP} 3 \mathrm{HT}}>E_{\mathrm{vGQDs}}>E_{\mathrm{vPCBM}}$ as illustrated in Figure 8(b) [6]. Additionally, a noticeable trend can be seen that $J_{\mathrm{SC}}$ reaches peak value in $2 \mathrm{mg}$ GQD-doping sample, then decreases with a higher dopant amount $(3 \mathrm{mg})$ and drops to minimum in $4 \mathrm{mg}$ GQD-doping samples. This can be explained as the GQD dopants gradually increase, more GQDs are at the interstitial positions between P3HT and PCBM, electrons and holes are transported easily to both electrodes which helps increase the efficiency. However, when the GQD doping amount further escalates, $J_{\mathrm{SC}}$ is not much improved since too much GQDs and different particle size can create defects or unexpected electron/hole traps. This keeps $J_{\mathrm{SC}}$ values nearly saturating or going down. Consequently, the 2-milligram GQD-doping amount in $2 \mathrm{ml}$ of $\mathrm{P} 3 \mathrm{HT}$ and $18 \mathrm{mg} / \mathrm{ml}$ of PCBM brings the highest overall efficiency of $1.43 \%$ compared with $0.99 \%$ of undoped samples. This is a noteworthy efficiency enhancement of more than $44 \%$.

\section{Conclusion}

We succeeded in fabricating graphene quantum dots from graphene oxide sheets with a microwave-assisted hydrothermal method. This approach is quite simple, cost-effective, and time-saving (10 minutes) compared with prolonged conventional methods (several hours). Graphene nanoparticle size was distributed in a narrow range from 2 to $8 \mathrm{~nm}$. The synthesized GQDs had good dissolution in water and strong blue emission under excitation of UV $365 \mathrm{~nm}$. GQDs had Ec and Ev levels suitable for HOMO and LUMO values of P3HT and PCBM and played the significant role as the hole transport layer. Acting as intermediate buffering layers, GQDs helped to lower potential difference between active layers and electrodes. This increased the short-circuit current density $\left(J_{\mathrm{SC}}\right)$ from $4.11 \mathrm{~mA} / \mathrm{cm}^{2}$ (no GQD doping) to $6.31 \mathrm{~mA} / \mathrm{cm}^{2}$ (2-milligram GQD doping). Correspondingly, the overall efficiency reaches the highest value of $1.43 \%$ (optimal doping samples) compared with $0.99 \%$ of no doping samples, a remarkable rise $44 \%$ of efficiency.

\section{Data Availability}

The data used to support the findings of this study are available from the corresponding authors upon request.

\section{Conflicts of Interest}

The authors declare that they have no conflicts of interest.

\section{Acknowledgments}

This research is funded by the Viet Nam National University, Ho Chi Minh City (VNU-HCM) (grant number C2017-18-25).

\section{References}

[1] S. Wang, Z. Li, X. Xu, G. Zhang, Y. Li, and Q. Peng, "Aminofunctionalized graphene quantum dots as cathode interlayer for efficient organic solar cells: quantum dot size on interfacial modification ability and photovoltaic performance," Advanced Materials Interfaces, vol. 6, no. 3, article 1801480, 2019.

[2] X. Chen and L. T. Yan, "Application of reduced graphene oxide and graphene quantum dots in PTB7:PC71BM polymer solar cells," Key Engineering Materials, vol. 768, pp. 114-118, 2018.

[3] L. Zhang, Z. C. Ding, T. Tong, and J. Liu, “Tuning the work functions of graphene quantum dot-modified electrodes for polymer solar cell applications," Nanoscale, vol. 9, no. 10, pp. 3524-3529, 2017.

[4] M. Li, W. Ni, B. Kan et al., "Graphene quantum dots as the hole transport layer material for high-performance organic solar cells," Physical Chemistry Chemical Physics, vol. 15, no. 43, pp. 18973-18978, 2013.

[5] P. R. Berger and M. Kim, "Polymer solar cells: P3HT:PCBM and beyond," Journal of Renewable and Sustainable Energy, vol. 10, article 13508, 2018.

[6] F. Li, L. Kou, W. Chen, C. Wu, and T. Guo, "Enhancing the short-circuit current and power conversion efficiency of polymer solar cells with graphene quantum dots derived from double-walled carbon nanotubes," NPG Asia Materials, vol. 5, no. 8, pp. e60-e64, 2013.

[7] H. Gaspar, F. Figueira, L. Pereira, A. Mendes, J. C. Viana, and G. Bernardo, "Recent developments in the optimization of the bulk heterojunction morphology of polymer: Fullerene solar cells," Materials, vol. 11, no. 12, article 2560, 2018.

[8] J. A. Luceño-Sánchez, A. M. Díez-Pascual, and R. P. Capilla, "Materials for photovoltaics: State of art and recent developments," International Journal of Molecular Sciences, vol. 20, no. 4, p. 976, 2019.

[9] F. Haque, M. M. Rahman, M. A. Al Mahmud, M. S. Reza, M. Akter, and A. H. M. Z. Karim, "Chemically converted graphene as a hole transport layer (HTL) inorganic photovoltaics (OPVS)," Engineering International, vol. 6, no. 1, pp. 7-20, 2018.

[10] M. A. Green, Y. Hishikawa, E. D. Dunlop et al., "Solar cell efficiency tables (version 53)," Progress in Photovoltaics: Research and Applications, vol. 27, no. 1, pp. 3-12, 2019.

[11] R. Kisslinger, W. Hua, and K. Shankar, "Bulk heterojunction solar cells based on blends of conjugated polymers with II-VI and IV-VI inorganic semiconductor quantum dots," Polymers, vol. 9, no. 12, p. 35, 2017.

[12] J. Liu, Y. Xue, Y. Gao, D. Yu, M. Durstock, and L. Dai, "Hole and electron extraction layers based on graphene oxide derivatives for high-performance bulk heterojunction solar cells," Advanced Materials, vol. 24, no. 17, pp. 2228-2233, 2012.

[13] T. Majumder, K. Debnath, S. Dhar, J. J. L. Hmar, and S. P. Mondal, "Nitrogen-doped graphene quantum dot-decorated $\mathrm{ZnO}$ nanorods for improved electrochemical solar energy conversion," Energy Technology, vol. 4, no. 8, pp. 950-958, 2016. 
[14] G. P. C. Drummen, "Quantum dots-from synthesis to applications in biomedicine and life sciences," International Journal of Molecular Sciences, vol. 11, no. 1, pp. 154-163, 2010.

[15] M. L. Tsai, W. C. Tu, L. Tang et al., "Efficiency enhancement of silicon heterojunction solar cells via photon management using graphene quantum dot as downconverters," Nano Letters, vol. 16, no. 1, pp. 309-313, 2016.

[16] P. Tian, L. Tang, K. S. Teng, and S. P. Lau, "Graphene quantum dots from chemistry to applications," Materials Today Chemistry, vol. 10, pp. 221-258, 2018.

[17] M. Kaur, M. Kaur, and V. K. Sharma, "Nitrogen-doped graphene and graphene quantum dots: a review onsynthesis and applications in energy, sensors and environment," Advances in Colloid and Interface Science, vol. 259, pp. 44-64, 2018.

[18] J. K. Kim, S. J. Kim, M. J. Park et al., "Surface-engineered graphene quantum dots incorporated into polymer layers for high performance organic photovoltaics," Scientific Reports, vol. 5, article 14276, 2015.

[19] Z. Ding, Z. Hao, B. Meng, Z. Xie, J. Liu, and L. Dai, "Few-layered graphene quantum dots as efficient hole-extraction layer for high- performance polymer solar cells," Nano Energy, vol. 15, pp. 186-192, 2015.

[20] M. R. Kim and D. Ma, "Quantum-dot-based solar cells: recent advances, strategies, and challenges," Journal of Physical Chemistry Letters, vol. 6, no. 1, pp. 85-99, 2015.

[21] L. Wang, W. Li, B. Wu, Z. Li, D. Pan, and M. Wu, "Room-temperature synthesis of graphene quantum dots via electronbeam irradiation and their application in cell imaging," Chemical Engineering Journal, vol. 309, pp. 374-380, 2017.

[22] J. Lu, P. S. E. Yeo, C. K. Gan, P. Wu, and K. P. Loh, "Transforming $\mathrm{C}_{60}$ molecules into graphene quantum dots," Nature Nanotechnology, vol. 6, no. 4, pp. 247-252, 2011.

[23] J. Peng, W. Gao, B. K. Gupta et al., "Graphene quantum dots derived from carbon fibers," Nano Letters, vol. 12, no. 2, pp. 844-849, 2012.

[24] S. Paulo, E. Palomares, and E. Martinez-Ferrero, "Graphene and carbon quantum dot-based materials in photovoltaic devices: from synthesis to applications," Nanomaterials, vol. 6, no. 9, article 157, 2016.

[25] H. Y. Nguyen, X. H. Le, and N. T. Dao, "Microwave-assisted synthesis of graphene quantum dots and nitrogen-doped graphene quantum dots: Raman characterization and their optical properties," Advances in Natural Sciences: Nanoscience and Nanotechnology, vol. 10, no. 2, article 025005, 2019.

[26] P. Yang, Z. Zhu, M. Chen, W. Chen, and X. Zhou, "Microwave-assisted synthesis of xylan-derived carbon quantum dots for tetracycline sensing," Optical Materials, vol. 85, pp. 329336, 2018.

[27] M. Zhang, L. Bai, W. Shang et al., "Facile synthesis of watersoluble, highly fluorescent graphene quantum dots as a robust biological label for stem cells," Journal of Materials Chemistry, vol. 22, no. 15, pp. 7461-7467, 2012.

[28] T. Van Tam, T. M. Altahtamouni, V. Le Minh, H. K. P. Ha, N. T. K. Chung, and D. Van Thuan, "One-pot microwaveassisted green synthesis of amine-functionalized graphene quantum dots for high visible light photocatalytic application," Comptes Rendus Chimie, vol. 22, no. 11-12, pp. 822-828, 2019.

[29] H. Sun, L. Wu, W. Wei, and X. Qu, "Recent advances in graphene quantum dots for sensing," Materials Today, vol. 16, no. 11, pp. 433-442, 2013.
[30] Z. Luo, G. Qi, K. Chen et al., "Microwave-assisted preparation of white fluorescent graphene quantum dots as a novel phosphor for enhanced white-light-emitting diodes," Advanced Functional Materials, vol. 26, no. 16, pp. 2739-2744, 2016.

[31] Z. Luo, D. Yang, G. Qi et al., "Microwave-assisted solvothermal preparation of nitrogen and sulfur co-doped reduced graphene oxide and graphene quantum dots hybrids for highly efficient oxygen reduction," Journal of Materials Chemistry A, vol. 2, no. 48, pp. 20605-20611, 2014.

[32] A. Kalluri, D. Debnath, B. Dharmadhikari, and P. Patra, "Graphene Quantum Dots: Synthesis and Applications," in Methods in Enzymology, vol. 609Elsevier Inc., 1st edition, 2018.

[33] H. Tetsuka, R. Asahi, A. Nagoya et al., "Optically tunable amino-functionalized graphene quantum dots," Advanced Materials, vol. 24, no. 39, pp. 5333-5338, 2012.

[34] L. Li, G. Wu, G. Yang, J. Peng, J. Zhao, and J. J. Zhu, "Focusing on luminescent graphene quantum dots: current status and future perspectives," Nanoscale, vol. 5, no. 10, pp. 4015-4039, 2013.

[35] C. Hu, Y. Liu, Y. Yang et al., “One-step preparation of nitrogen-doped graphenequantum dots from oxidized debris of graphene oxide," Journal of Materials Chemistry B, vol. 1, no. 1, pp. 39-42, 2013.

[36] B. Zheng, Y. Chen, P. Li et al., "Ultrafast ammonia-driven, microwave-assisted synthesis of nitrogen-doped graphene quantum dots and their optical properties," Nanophotonics, vol. 6, no. 1, pp. 259-267, 2017.

[37] Y. Dong, J. Shao, C. Chen et al., "Blue luminescent graphene quantum dots and graphene oxide prepared by tuning the carbonization degree of citric acid," Carbon, vol. 50, no. 12, pp. 4738-4743, 2012.

[38] Y. D. Shang, X. H. Chen, W. H. Ma, S. Y. Li, Y. C. Wang, and F. W. Xiang, "Preparation and optical properties research on graphene quantum dots," Key Engineering Materials, vol. 727, pp. 303-308, 2017.

[39] L. Shahriary and A. A. Athawale, "Graphene oxide synthesized by using modified hummers approach," International Journal of Renewable Energy and Environmental Engineering, vol. 2, no. 1, pp. 58-63, 2014.

[40] S. Kumar, S. K. T. Aziz, O. Girshevitz, and G. D. Nessim, "One-step synthesis of N-doped graphene quantum dots from chitosan as a sole precursor using chemical vapor deposition," Journal of Physical Chemistry C, vol. 122, no. 4, pp. 2343-2349, 2018.

[41] D. Pan, J. Zhang, Z. Li, and M. Wu, "Hydrothermal route for cutting graphene sheets into blue-luminescent graphene quantum dots," Advanced Materials, vol. 22, no. 6, pp. 734-738, 2010.

[42] S. Zhu, J. Zhang, X. Liu et al., "Graphene quantum dots with controllable surface oxidation, tunable fluorescence and upconversion emission," RSC Advances, vol. 2, no. 7, pp. 2717$2720,2012$. 